\title{
CUTANEOUS HORN IN ACTINIC KERATOSIS-A CASE REPORT
}

\section{Shanmugasundaram ${ }^{1}$.}

1. Assistant Professor, Department of Dermatology, Karuna Medical College and Hospital, Chittoor, Palakad, Kerala.

\section{CORRESPONDING AUTHOR}

Dr. V. Shanmugasundaram M.D., 411, G.V. Residency, Sowripalayam, Coimbatore- 641028.

Tamil Nadu.

Email-shanmugammd@yahoo.com

\section{HOW TO CITE THIS ARTICLE:}

V. Shanmugasundaram. "Cutaneous Horn in Actinic Keratosis- A Case Report". Journal of Evolution of Medical and Dental Sciences 2013; Vol2, Issue 24, June 17; Page: 4291-4293.

\begin{abstract}
A cutaneous horn is a relatively rare tumour, most often arising from sun exposed skin in elderly men, usually after fifth decade. The tumour is often conical, consisting of marked retention of stratum corneum. Cutaneous horn occurs in association with or as a response to a wide variety of underlying benign, premalignant and malignant cutaneous diseases. Thus the importance of accurate determination of nature of the condition at the base of lesion, surgery is the treatment of choice. Here we report a case of cutaneous horn in actinic keratosis.
\end{abstract}

KEYWORDS: Cutaneous horn, Cornu cutaneum, Actinic keratosis, Seborrhic keratosis.

INTRODUCTION: A cutaneous horn is a conical projection of hyperkeratotic epidermis. Though grossly resembling an animal horn, it lacks a bony core. It may arise from any part of body, and only $30 \%$ arise from the face and scalp (1).They are thought to result from underlying benign, premalignant or malignant pathology(2). Cutaneous horn has been noticed on top of many clinical conditions like keratoacanthoma, actinic keratosis, wart, molluscum contagiosum, seborrheic keratosis, basal cell carcinoma, squamous cell carcinoma. Here we report a patient of cutaneous horn on top of actinic keratosis.

CASE REPORT: A 64 year old male, farmer presented with horny growth on the right side of vermilion border of upper lip for 2years duration (fig). Initially patient noticed small itchy pigmented plaque over upper lip and gradually developed horny growth over the plaque. Also there is hyperkeratotic plaque with fissuring seen over right angle mouth; suggestive of actinic cheilitis (fig) .There was no history of pain or discharge over lesion.

On examination there was a hyperkeratotic horny growth arising over a hyperpigmented plaque, measuring $1 \times 1 \mathrm{~cm}$ on right side of vermilion border of upper lip, Angle of mouth on Right side showed minimally pigmented hyperkeratotic plaque with fissuring and raw areas. There was no pain, discharge or bleeding over growth. No regional lymphadenopathy. Clinical diagnosis of cutaneous horn over seborrheic keratosis or actinic keratosis was made. Excision biopsy of the upper lip was done under local anaesthesia and similarly punch biopsy of the lesion over angle of mouth was done and specimen sent for histopathological examination. There is parakeratosis, 
hyperkeratosis, loss of granular layer, thickened epidermis, nuclear atypia and dermis showed actinic elastosis and chronic inflammatory infiltrate on histopathological examination.

DISCUSSION: Cutaneous horn or cornu cutaneum are elongated, keratinous projections from the skin, ranging in size from a few milli meters to many centimetres that resembles a miniature horn. The base of the horn may be flat, nodular or crateriform. The horn composed of compacted Keratin. The distribution of cutaneous horn usually in sun exposed areas, particularly the face, pinna, nose, forearm, and dorsal aspect of hand (3). They may also develops over the areas not exposed to sunlight such as the penis, mucosal lower lip, and nasal vestibule $(4,5)$.Malignancy is present in 16 $20 \%$ of cases, with squamous cell carcinoma being the most common type(6).Tenderness at base of the lesion and larger the size favour malignancy(7). Most cutaneous horn arise from actinic keratosis but they may also result from seborrheic keratoses, warts, keratoacanthoma, squamous cell carcinoma, basal cell carcinoma.

Actinic keratosis is a premalignant condition. The lesion starts as flat scaly areas and later grows into a large wart like lesions. It is commonly ranges between 2-6 millimeter in size, may be dark, light, tan, pink, red or combination of all these colour, occurs on sun exposed areas of the body such as face, ears, neck, scalp, chest, back of hands, forearm and lips. Up to $20 \%$ of untreated actinic keratosis can progress to malignancy. Histologically there is thickened stratum corneum with scattered areas of parakeratosis. The base of horn will display the characteristic feature of the pathologic process responsible for the development of the horn $(8,9$.).

Excision biopsy of the lesion and histopathological examination to rule out malignancy is mandatory and malignancy should be excised with appropriate margins and evaluate for metastasis. A careful physical examination of the lymph nodes draining the area of lesion is required.

A treatment option includes wide surgical excision, electrocautery, cryotherapy, carbon dioxide or Nd YAG laser (10).

CONCLUSION: Cutaneous horn is a relatively potential malignant tumour. Require surgical excision and histopathological examination to exclude underlying malignant pathology.

\section{REFERENCES:}

1. Bondeson J. Everard Home, John Hunter, and cutaneous horn: a historical review. Am J Dermatopathol.2001; 23:362-9.

2. Yu RCH, Pryce DW, MacFarlane AW, Stewart TW: A histopathological study of 643 cutaneous horns. Br J Dermatol 1991; 124:449-452.

3. Copcu E, Sivrioglu N, Culhaci N. Cutaneous horns: are these lesions as innocent as they seem to be? World J Such Oncol.2004; 2:18.

4. Rekha A, Ravi A. Cornu cutaneum - cutaneous horn on the penis. Indian J Surg. 2004;66:2967

5. Mutaf M. A rare perioral lesion: cutaneous horn of the lower lip.Eur J Plastic Surg. 2007; 29:339-41.

6. Solivan GA, Smith KJ, James WD. Cutaneous horn of the penis: Its association with squamous cell carcinoma and HPV-16 infections. J Am Acad Dermatol.1990;23:969-72. 


\section{CASE REPORT}

7. Tauro LF, Matrix JJS, John SK, Kumar KP.Cornu cutaneum at an unusual site. Indian J Plast Surg 2006;39:76-8.

8. GouldJW, Brodell RT. Cutaneous horn associated with verruca vulgaris. Cutis.1999; 64:1112.

9. Mencia- Gutierrez E, Gutierrez-Diaz E, Redondo-MarcosI, Ricky JR, Garcia-Torre JP. Cutaneous horns of the eyelid: A Clinicopathological study of 48 cases. J Cut an Pathol. 2004; 31: 539-43.

10. Lowe FC, McCullough AR. Cutaneous horn of the penis: An approach to management: Case report and review of literature. J Am Acad Dermatol.1985; 13: 369-73.

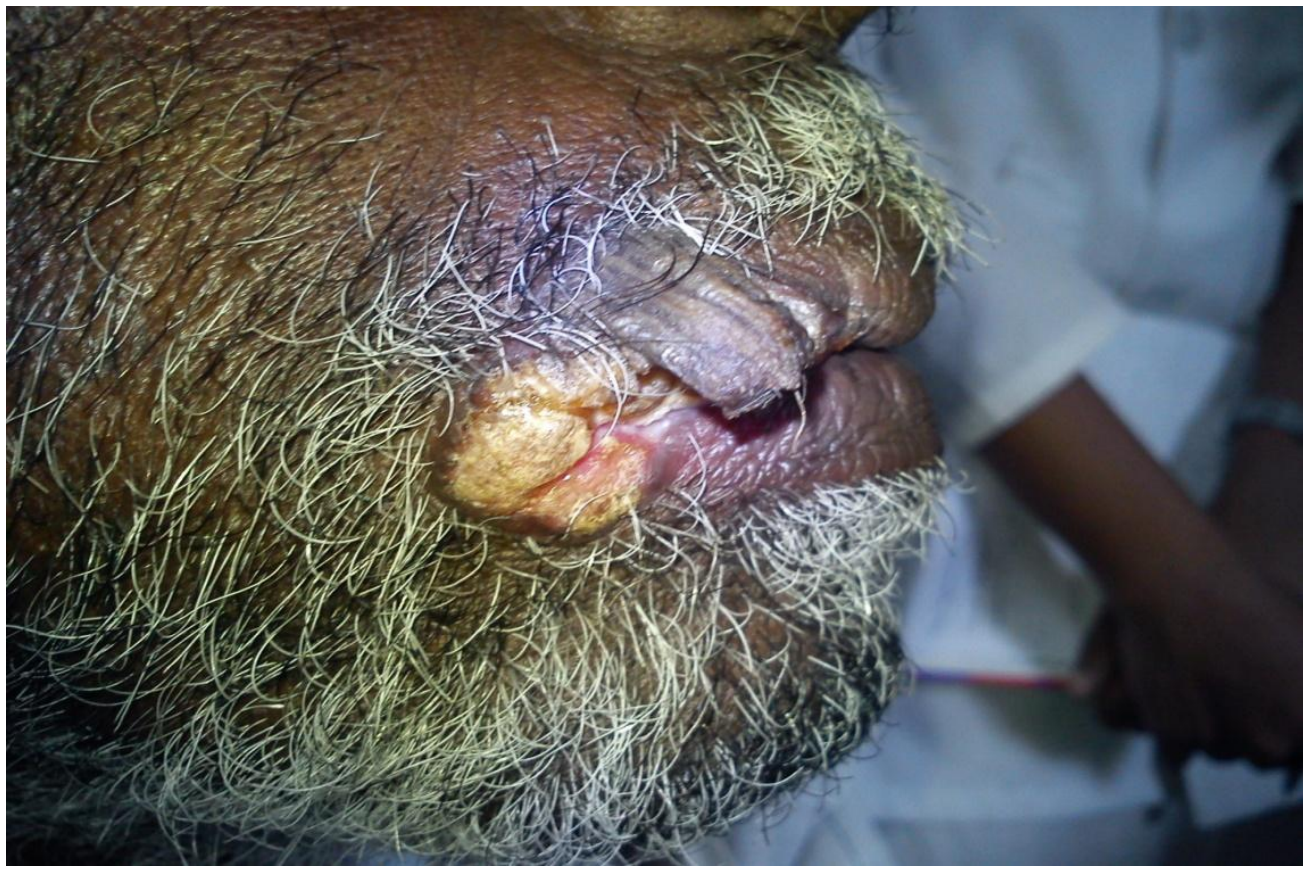

Cutaneous Horn 